\title{
PIRILAMPOS EM NOITE DE CHUVA LITERATURA BRASILEIRA ATUAL E FORMAS DE (IN)VISIBILIDADE
}

RESUMO: Este artigo é uma reflexão sobre as formas de visibilidade dos escritores brasileiros contemporâneos dentro do espaço nacional a partir de um olhar às listas de alguns críiticos/leitores da produção contemporânea. Aborda também uma ideia de literatura implicada no gesto mesmo do autor se fazer visível, tomada aqui como uma "literatura expandida". Por fim, o artigo apresenta alguns resultados da pesquisa "A literatura brasileira atual no mapa da América Latina".

PALAVRAS-CHAVE: Visibilidade. Literatura contemporânea. Literatura brasileira.

\section{FIREFLIES IN A RAINY NIGHT CONTEMPORARY BRAZILIAN LITERATURE AND (IN)VISIBILITY FORMS}

ABSTRACT: This article is a reflection on the forms of visibility of contemporary Brazilian writers within the national space from a glance at the lists of some critics / readers of contemporary production. It also deals with an idea of literature involved in the author same gesture to make visible, taken here as an "expanded literature". Finally, the article presents some results of the survey "A literatura brasileira atual no mapa da América Latina".

KEYWORDS: Visibility. Contemporary literature. Brazilian literature.

leda Magri é professora adjunta do departamento de Literatura Brasileira e Teoria da Literatura da Universidade Estadual do Rio de Janeiro. 


\section{PIRILAMPOS EM NOITE DE CHUVA LITERATURA BRASILEIRA ATUAL E FORMAS DE (IN)VISIBILIDADE}

leda Magri

\section{APARECIMENTO/DESAPARECIMENTO}

"Até aquele dia, exatamente o dia de sua aposentadoria, a ideia de chegar a ter sucesso na vida sempre o aterrorizou." Assim começa a história de Anatol, escritor secreto no país onde nasceu e de onde partira na juventude para depois voltar como estrangeiro. Durante quarenta anos, como professor de educação física, Anatol escreveu sete romances e escondeu-os num baú e uma pequena introdução a um livro de fotografias esportivas fez com que o faro do editor e poeta de nome impronunciável - Hvulac - anunciasse a toda a ilha: "- Aqui há um autor." Estamos em "A arte de desaparecer", de Suicídios exemplares de Enrique Vila-Matas. ${ }^{1} \mathrm{~A}$ sanha persecutória de um editor caça-talentos comprometido em elevar a glória nacional faz de Anatol um escritor condenado ao desaparecimento: para deixar sua obra ser publicada, o autor deve desaparecer.

Esta é precisamente a aventura literária que coloca em cena o tema do autor secreto e, me parece, parte de uma convicção, a de que é preciso fazer valer mais a obra que o nome do autor, que a ânsia pelo reconhecimento. Diante de um mundo literário em que vigora a luta pelo reconhecimento, a luta pelo direito de existir como escritor; diante de um mundo de editores à caça de talentos jovens; diante de muitos nomes de autores sem segundos livros, uma defesa quase lírica do direito ao desaparecimento.

Por outro lado, César Aira, dizia ainda na década de 1990: o sistema de crença que diz que alguém é um escritor não se sustenta pelos livros que esse alguém escreve. "Qualquer escritor renunciaria a seus livros se não precisasse deles para construir um mito." ${ }^{2}$ Para fazer com que as pessoas acreditem que

\footnotetext{
${ }^{1}$ VILA-MATAS, Enrique. Suicídios exemplares. Trad. Carla Branco. São Paulo: Cosac Naify, 2009, p. 73-88.

2 JOSEF, Bella. Diálogos oblíquos. 34 escritores falam de literatura latino-americana. Rio de Janeiro: Francisco Alves, 1999, p. 41-50.
} 
ele é realmente um escritor. A Roberto Bolaño também interessavam os poetas latino-americanos sem nenhum livro, cuja obra era o próprio corpo e a voz que animou as discussões em torno da poesia na perdida década de 1970. Mário Santiago Papasquiaro era o maior deles para Bolaño e somente depois do sucesso de Os detetives selvagens é que foi postumamente publicado pela Fondo de Cultura, no México.

É assim que vemos, hoje, no movimento que faz visível o aparecimento de alguma literatura, o frágil equilíbrio entre o escritor que conquistou o reconhecimento, o direito de existir como escritor e que quer desaparecer um pouco para que apareçam seus livros ou seus gestos de escrita e o autor que está em luta pelo direito de existir, de se constituir enquanto escritor para que seus livros passem a ser vistos e lidos.

\section{LITERATURA EXPANDIDA}

O escritor, professor e crítico literário argentino Alan Pauls usa o termo literatura expandida para pensar o gesto que vai da obra ou do texto "à arte de viver na arte" como uma vontade de des-especificidade da literatura. Ele parte do investimento excêntrico de autores como Héctor Libertella (que se declara uma sorte de autoeditor para quem o que menos importa é o livro pronto, que pensa-se enquanto política editorial em que escritura, pintura e grafismo fazem da literatura uma "escultura gráfica" ou uma "ideografia rupestre"); Mario Bellatin (que inclui em cada um de seus livros uma fotografia sua exibindo a prótese, sempre diferente, sempre outra, acoplada à falta de seu braço direito e que tem como projeto publicar 100 mil livros, num desafio evidente à ideia de "indústria do livro"); e César Aira (que tem mais romances que anos e que inunda o sistema literário com esse excesso de produção somente para dizer que uma obra, que um livro, não é nada, editando-os sempre em editoras mínimas, desconhecidas, tirando seus livros da circulação e do modo de distribuição em grandes redes), para mostrar que todos eles impõem suas performances, seus gestos, seus procedimentos como parte configuradora de sua escrita. "Essa série de gestos objetivam uma maneira artística de estar presente, corporizar-se, intervir em pessoa no suporte que é a dimensão visível do mundo" ${ }^{3}$, "enunciam um testamento estético-político, uma atitude,

\footnotetext{
${ }^{3}$ PAULS, Alan. Temas lentos. Chile: Ediciones Universidad Diego Portales, 2012, p. 174. As citações seguintes estão nas p. 178 e 181 respectivamente.
} 
uma estetização de si" que poderia ser chamada de "literatura em pessoa" ou "literatura expandida".

Alan Pauls sustenta que essa literatura expandida - "enquanto prática que opera com textos e ações, narrações e jogos de relação, gêneros literários e montagens que operam sobre a vida cotidiana" - não é o desvio aberrante que trai o sistema da especificidade literária, ao contrário, é justamente a concepção, o regime e o programa estético que se propõe a suplantá-lo. Para Alan Pauls, "esses excêntricos fazem com suas personalidades o mesmo que com suas palavras: buscam alienar a literatura, desensimesmá-la, libertá-la da linhagem do próprio" e não é por acaso que os três compartilham uma atração forte pelas artes plásticas. A literatura expandida promovida por esses autores deixa aparecer uma forte conexão com a arte contemporânea, em especial com a performance e com a arte conceitual e, partindo do gesto de Duchamp, que "inventa que a arte não é uma questão de obras, nem de beleza, nem de formas: é um assunto de decisão, de tomar decisões e aplicá-las sobre objetos, corpos, espaços, instituições", criam uma espécie de "vida ready-made".

Dessa maneira, a literatura expandida "critica a solidez, a monumentalidade, a arquitetura autoritária, a autarquia, o desdém do contexto, a memorialidade" da ideia de obra. A isso, a literatura expandida opõe, por um lado, a potência do efêmero, o furtivo, o que desafia o registro, o irrisório: "gestos, ações, posturas e imposturas, comportamentos, efeitos de personalidade, prenúncio de situações, espetáculos da vida cotidiana"; por outro, algo que está muito ligado à tomada de decisões da arte conceitual e que Pauls propõe chamar de "política da regra". Se trata, com efeito, de "inventar regras, axiomas, obrigações": para Aira, escrever uma página por dia, não corrigir nunca, incorporar fatos do presente imediato quando o relato não avança, publicar sempre em editoras diferentes; para Bellatin, a lei é "não o produto, mas a possibilidade, não o resultado mas o processo", os livros como manifestações acidentais; para Libertella, a literatura como intervenção plástica.

O termo literatura expandida, foi a princípio derivado do estudo de Rosalind Krauss sobre a escultura como aquilo que se dá no espaço duplamente negativo de "não-monumento" e "não-arquitetura, situando-se no espaço aberto e maleável de uma troca dinâmica entre paisagem/arquitetura/escultura. No contexto brasileiro, Dominique Gonzalez-Foerster (França, 1965), a performer, artista visual e "escritora frustrada", como gosta de se apresentar, que tem a exposição permanente Desert Park, em Inhotim, usou o termo em 
entrevista a Ana Pato, cuja dissertação de mestrado sobre a artista veio a público justamente com o título "Literatura expandida - arquivo e citação na obra de Dominique Gonzalez-Foerster". O trabalho de Ana Pato se dá a partir da teorização de uma ideia de arquivo que não cabe mais em um lugar material e que desliza para a ideia de diagrama, conforme teoriza Foucault com o estudo das formas-prisão e Deleuze em seu livro sobre Foucault. A cultura é, pelo gesto apropriativo de Dominique, concebida como uma virtualidade que toma todos os lugares e, desta forma, se apossa do gesto criativo do autor/ artista. A este reserva-se apenas a possibilidade de mesclar e de dar nova forma de visibilidade ao que já existe como obra. O artista ou autor seria uma espécie de sampler, para usar a linguagem da música.

Em Dominique, o termo não designa "a arte de viver em arte", como em Alan Pauls, mas o gesto de combinar elementos de todas as áreas da cultura, gesto que define seu trabalho. Ela se apossa, por exemplo, de Roberto Bolaño, Enrique Vila-Matas e J. G. Ballard, os autores mais presentes em suas instalações, e de esculturas de outros artistas como Louise Bourgois, Helio Oiticica, e até de um orelhão da cidade do Rio de Janeiro, como em Park - a plan for escape, de 2002. Ela cria ambientes a partir da ficção científica, que citam, assim, artistas e obras já conhecidos de seu público. Ao "transportar" elementos de um ambiente a outro, artificial, e ao "corromper as citações, na medida em que os alegoriza, ou seja, na medida em que os esvazia de seus significados próprios e lhes empresta novos, Dominique diz realizar uma escrita não mais alfabética, mas composta de pistas e imagens. A isso chama de literatura expandida." 4

Embora muito presente na arte recente, Florência Garramuño ${ }^{5}$ nos lembra que em Silviano Santiago, já se vê desde 1970 esse gesto de construção de formas de questionamento da autonomia estética que conformou um dos parâmetros centrais de constituição do moderno. Em sua literatura de ficção, mas também em seus textos teóricos, como "O entre-lugar do discurso latinoamericano" ${ }^{6}$, Silviano Santiago está sempre contrastando a noção de originalidade e de pureza. Repetições, retornos, releituras e reescrituras manifestam

\footnotetext{
${ }^{4}$ PATO, Ana. Literatura expandida. Arquivo e citação na obra de Dominique Gonzalez-Foerster. São Paulo: Sesc-SP e Associação Cultural Videobrasil, 2013, p. 89.

${ }^{5}$ GARRAMUÑO, Florencia. La experiencia opaca. Literatura y desencanto. Buenos Aires: Fondo de Cultura Económica de Argentina, 2009.

${ }^{6}$ SANTIAGO, Silviano. Uma literatura nos trópicos. Ensaios sobre dependência cultural. São Paulo: Perspectiva, 1978.
} 
essas práticas de contestação e inscrevem-se na ideia deleuzeana de repetição como instauradora de diferença. E o que dizer de Oswald, justamente citado no referido texto de Santiago, que diz que a Alemanha nazista precisava "se mulatizar", se carnavalizar, destruindo qualquer traço de unidade e pureza? Também Haroldo de Campos é capaz de fazer retroceder a Oswald e sua noção de antropofagia esse gesto de destruição de toda ideia de pureza, ou seja, no coração mesmo do modernismo brasileiro e ainda antes, a Machado de Assis e sua metáfora da cabeça como "bucho ruminante" ${ }^{7}$.

Uma literatura expandida merece uma leitura expandida, então, e que precisa se estender também para o estudo das formas de visibilidade a que se lançam os autores, às vezes um gesto mais importante do que o próprio livro.

\section{PANORAMA BRASILEIRO (?)}

No Brasil, é principalmente Flora Sussekind a crítica que está atenta para essa literatura que se constitui no que ela chama de coro, uma multiplicidade de vozes, elementos não verbais e de uma sobreposição de registros e modos expressivos diversos. "Coralidades nas quais se observa, igualmente, um tensionamento propositado de gêneros, repertório e categorias basilares à inclusão textual em terreno reconhecidamente literário, fazendo dessas encruzilhadas meio desfocadas de falas e ruídos uma forma de interrogação simultânea tanto da hora histórica, quanto do campo mesmo da literatura." ${ }^{8}$

Flora Sussekind lê essa literatura justamente no seu tensionamento com outros gêneros, o teatro, o cinema, as artes plásticas e lê mesmo essas outras artes em sua tessitura entre gêneros. Uma literatura que se conecta com o passado, por exemplo em $O$ Guesa, nos romances-experimentos de Oswald de Andrade, em seu teatro e mesmo em alguma poesia mais recente, como a de Chico Alvim, Augusto de Campos e Carlito Azevedo, que estaria no começo desse caminho que ela vê em meio agora. Seu texto acusa duas identificações: "coros dissonantes", essas vozes multíplices, essa "figuração informe de

\footnotetext{
${ }^{7}$ CAMPOS, Haroldo de. Da razão antropofágica: diálogo e diferença na cultura brasileira. In: Metalinguagem e outras metas. Ensaios de teoria e crítica literárias. São Paulo: Perspectiva, 2006.

${ }^{8}$ SUSSEKIND, Flora. Coros dissonantes: objetos verbais não identificados na literatura brasileira contemporânea. In: LINS, Vera; PENJON, Jacqueline; SUSSEKIND, Flora (Orgs.). Interpretações literárias do Brasil moderno e contemporâneo. Rio de Janeiro: 7Letras, 2014, p. 203-212.
} 
vozes" e "Objetos verbais não identificáveis", a saída ou a dificuldade ou a impossibilidade de classificação.

A crítica lê autores contemporâneos bem conhecidos do público leitor brasileiro (sempre o especializado, formado, portanto, praticamente de pesquisadores, professores e pelos próprios escritores) de qualquer forma, autores que já "existem" para o sistema literário brasileiro: André Sant'Anna, Lourenço Mutarelli, Verônica Stigger, Beatriz Bracher, Marília Garcia, Nuno Ramos e Bernardo Carvalho. E um menos conhecido, menos citado pelos críticos: Antonio Geraldo Figueiredo Ferreira. Todos unidos por um tênue fio, justamente o que merece a designação de "literatura exigente": aquela feita por "autores para os quais cada processo de formalização é igualmente problemático". Entrevemos aqui aquele critério de Alan Pauls, que faz emergir muito mais o gesto do escritor em sua procura pelo literário, em sua problematização permanente do literário, do que o resultado em si, o livro propriamente dito, se bem que o gesto e o livro não estejam longe um do outro, um pode ser entrevisto no outro, um se sustenta pelo outro. E assim, essa literatura se opõe a outra "cuja aparente experimentação é apenas uma espécie de prêt-à-porter literário baseado em técnicas já mais do que assimiladas, compradas prontas." (E aqui, talvez seja oportuno fazer notar, Flora responde a um artigo de Leyla Perrone-Moisés, no qual se faria "um contraste simplificador entre literatura exigente e literatura de mercado").

Há, e Flora Sussekind o vê, um outro gesto, personificado num texto de Luiz Ruffato, mas visível em vários narradores contemporâneos, pelos quais pode ser lida uma defesa da "obra bem feita" (Ruffato), do "contar bem uma história" (Daniel Galera), do controle do experimentalismo por si mesmo ( $\mathrm{Ma}$ nifesto Silvestre $)^{9}$ e, enfim, da profissionalização do escritor como direito à conquista do grande público, manutenção de contratos em editoras de maior lastro comercial e a tão almejada tradução para outras línguas, o que permite ao escritor (de fato?) existir fora dos limites nacionais. No Brasil, ao contrário dos exemplos de escritores em língua espanhola com que começo este artigo, mas certamente em consonância com outros escritores menos reconhecidos daqueles mesmos países, o escritor está ainda muito preocupado em conquistar um espaço para seus livros, empenhado em ser lido. Claro, para poder desaparecer é preciso primeiro aparecer.

\footnotetext{
${ }^{9}$ O GLOBO. Manifesto do Grupo Silvestre pela popularização da ficção. 2010. Prosa \& Verso.
} 
Beatriz Resende, no recente Possibilidades da nova escrita no Brasil, parte da evidência de uma "nova e maior visibilidade" dada "com a mudança na forma como somos agora recebidos no cenário internacional", para ler o momento presente da narrativa brasileira. Para ela, com a "ampliação do poder aquisitivo dos brasileiros como um todo", está em curso uma grande modificação, capaz de incluir novas camadas no consumo de arte e de literatura, cujo gosto vem se impondo no mercado. Ao lado desse crescimento interno, vê-se também uma mudança no mercado externo: de país unicamente receptor, o Brasil passa também a fornecedor de literatura. Ela lê, assim, um passo adiante na máxima modernista da atitude antropofágica: "Trata-se de formar um sistema literário com conceitos próprios do que é literatura, propondo ainda suspender limites entre as escritas literárias e as diversas expressões artísticas, numa troca de linguagens efetiva e não de empréstimos." ${ }^{10}$

Três evidências constituem essa nova literatura brasileira: 1. um princípio democrático que expõe novas subjetividades e reconfigura o termo literatura; 2. o rompimento com a tradição de afirmação da língua e de valores nacionais, visto principalmente no deslocamento das narrativas do espaço nacional; e 3. a ruptura com a tradição realista, documental e ficcional convivendo na mesma obra. Ela lê alguns autores que colocam em marcha as três evidências: Ferrez, com Fortaleza da desilusão, Manual prático do ódio e Capão pecado; Rubens Figueiredo, com Passageiro do fim do dia e Contos de Pedro; Bernardo Carvalho, especialmente com Filho da Mãe, sequência mais recente de uma trajetória de desenraizamento que vem desde Teatro (1998) e Mongólia (2003); Sérgio Sant'Anna, com Livro de Praga e João Paulo Cuenca, com 0 único final feliz para uma história de amor é um acidente; os três últimos autores todos participantes do projeto Amores expressos, cujo mote era uma viagem de um mês para qualquer lugar do mundo onde deveria ser ambientada uma história de amor, realizando de maneira oportuna a saída do espaço nacional para ambientação da narrativa.

Como literaturas que se inserem num conflito com a tradição realista, Beatriz lê Barba ensopada de sangue, de Daniel Galera, vendo ali uma tensão entre uma estrutura realista e a ruptura com o realismo evidente na quase sobrenaturalidade do encontro com um avô desaparecido e dado como morto numa região litorânea, cenário real, do sul do país. Figuram, ainda, como

\footnotetext{
${ }^{10}$ RESENDE, Beatriz. Possibilidades da nova escrita literária brasileira contemporânea. Rio de Janeiro: Revan/Faperj, 2014, p. 9-23.
} 
exemplos de uma literatura que suspende os limites entre o biográfico e o ficcional, os livros de Paloma Vidal, Algum lugar e Duas mãos, o de Michel Laub, Diário da queda e o de Beatriz Bracher, Meu amor.

A verdade é que cada crítico tem suas listas. Outro estudioso da literatura contemporânea feita no Brasil, João César de Castro Rocha, propõe o projeto "Literatura brasileira hoje", desenvolvido na UERJ, e que tem como propósito "questionar a transformação do escritor em autêntica persona pública, exposta na miríade de festivais literários que, felizmente, se organizam em todo o país."11 Para João César "solicita-se cada vez mais a presença física do escritor, porém, a tiragem de seus livros segue como se ainda estivéssemos em 2002... [data da primeira edição da Flip]. Vale dizer, o escritor é visto, incontáveis selfies são tiradas e devidamente compartilhadas, porém, seu texto não é lido, seu projeto literário sequer imaginado." ${ }^{12}$ Para sair desse impasse, sua lista mostra Ricardo Lísias, João Almino, Evando Nascimento (o projeto está em andamento, outros autores já foram convidados, mas seus nomes ainda não foram divulgados) todos convidados para conversas com os estudantes de graduação e pós-graduação em Letras daquela universidade com o diferencial de o escritor enviar alguns textos ou partes de um romance, preferencialmente de seu livro mais recente, para que seja lido pelo público antes do encontro. Crê-se, assim, que a "melhor forma de encarar os desafios atuais consiste em ler com olhos livres o que temos diante deles." E, parece, seria preciso ler também entre o autor como celebridade e o autor como "produtor de textos" ou "provedor de conteúdo". E ler com olhos livres significa também que a lista de convidados precisa variar os nomes.

Uma exigência, me parece, desponta dos textos dos três críticos: uma super abundância de produção e uma necessidade de atenção desmedida para que o crítico (e por extensão a universidade) não fique à reboque da super visibilidade construída sobre alguns escritores sem cair na busca pouco complexa circunscrita aos espaços de escuridão.

Até aqui, o que salta aos olhos é a minha leitura da perspectiva crítica e mesmo da abrangência da leitura crítica no ambiente literário do Rio de Janeiro. Infelizmente, cada Estado brasileiro sofre como se fosse um país inteiro, que necessita vencer seus próprios limites geoculturais pelo direito de existir no sistema literário nacional. Esse o diagnóstico mais perturbador: num

\footnotetext{
${ }^{11}$ ROCHA, João Cezar de Castro. Literatura Brasileira hoje: uma ideia. In: Pessoa, 21 abr. 2015. ${ }^{12}$ Ibidem.
} 
momento em que se reivindica um lugar no sistema-mundo para o Brasil, a clareza de que os autores estudados, lidos, publicados fora do Brasil, em sua maioria são autores do Sudeste do país ou que migraram, principalmente do Rio Grande do Sul, para esse centro dinamizador. José Luis Passos, professor na Universidade da Califórnia, e também autor do premiado e lindíssimo Sonâmbulo Amador (afinal, eu também tenho as minhas listas), em seu texto "As lições que a distância nos dá"13 conta uma anedota que advém de seu trabalho em sala de aula, anedota que ilustra bem o que digo sobre um sistema literário brasileiro: uma sua aluna pergunta: "Professor, o senhor é especialista em quê?", depois de pensar um pouco, não sem uma pequena perturbação, ele responde: "Em literatura brasileira". Argumentando que esta era uma área e não uma especialidade, ela refez a pergunta e ele respondeu, então, que havia publicado alguns artigos sobre Machado de Assis e sobre Mário de Andrade, ao que ela retruca: "Mário de Andrade e Machado de Assis? Professor, então o senhor é especialista em literatura sudestina".

\section{(IN)VISIBILIDADES}

Recentemente fui convidada a fazer a crônica do encontro com João Almino na UERJ e então descrevi um mundo da literatura brasileira onde 500 autores se equilibram sobre uma mesa de madeira não muito grande. Todos os meus poucos leitores acharam que era uma brincadeira: "500 autores? Inimaginável".

Nos surpreenderíamos de fato ao observar o número de autores publicados entre 2000 e 2014 no Brasil e que não constam de nenhuma das listas de "melhores escritores brasileiros com menos de 40 anos", "os 20 melhores" ou "autores premiados" etc. e que, claro, não frequentam o mapa da crítica, portanto. Contra em torno de 70 autores brasileiros em atuação hoje no Brasil com entre alta e média visibilidade, todos presentes em uma ou outra lista, de um ou outro crítico, podemos apresentar um número bastante expressivo: mais de 400 autores com o que chamaríamos de baixa ou nenhuma visibilidade, ou seja, publicam por editoras menores, mas também por grandes editoras (há autores da Companhia das Letras sem visibilidade alguma além da que o nome da própria editora pode oferecer), e seus nomes não constam

\footnotetext{
${ }^{13}$ MONTEIRO, Pedro Meira (Org.). A primeira aula. Trânsitos da literatura brasileira no estrangeiro. São Paulo: Itaú Cultural/Hedra, 2014, p. 42-51.
} 
de resenhas em jornais de grande circulação, da agenda literária das feiras e festas nem são lidos pelos júris dos prêmios. Talvez a maior vantagem dada pela existência desse mapa seja a possibilidade de ver todas as regiões brasileiras em contraste de visibilidade de sua produção. E outra: um olhar abrangente, quase total (seria ilusório?) da produção contemporânea.

O mapa foi construído (e ainda está em construção, numa nova fase agora) durante dois anos com um grupo de alunos de graduação, da Faculdade de Letras da Universidade Federal do Rio de Janeiro (UFRJ) ${ }^{14}$, fazendo o levantamento dos autores em atividade nos sites das principais editoras brasileiras. Delimitamos a pesquisa aos gêneros conto, romance e poesia, deixando de lado autores que só trabalham com crônica, biografia e outros gêneros considerados não literários (o que não deixa de merecer crítica quando falamos em leitura expandida). Se, primeiramente, a pesquisa se guiou diretamente pelas editoras, depois percebemos a impossibilidade de dar conta de todas, já que há muitas editoras novas, algumas sem catálogo online. Dessa forma, depois de analisados os catálogos da 7Letras, reconhecidamente uma das editoras que mais publica autores novos, da Companhia das Letras, uma das mais prestigiadas, da Cosac Naify, da Record, da Rocco e da Objetiva fomos às consideradas menores por terem um catálogo menos extenso, porém com um número considerável de autores, alguns presentes nas listas dos principais prêmios: Editora 34, Alfaguara, Hedra, Casa da Palavra, Confraria do Vento, Estação Liberdade, Grua, Ibis Libris, Imago, Leya e Planeta. Ao colocar os nomes dos autores no mapa, porém, percebemos a ausência de alguns já reconhecidos e redirecionamos a pesquisa às listas de autores premiados ou finalistas dos principais prêmios literários brasileiros, o Prêmio

\footnotetext{
${ }^{14}$ A pesquisa teve bolsa da Faperj e foi realizada no âmbito do pós-doutorado entre 2013 e 2015 e a formação do mapa revelou-se um trabalho complexo, que demandou imensa quantidade de horas de pesquisa e não teria sido possível sem o trabalho de verdadeira equipe desenvolvido em conjunto com alunos da graduação em Letras da Universidade Federal do Rio de Janeiro (UFRJ). São eles: Hélida Carvalho Lima, João Gabriel Kalili Marcelino, Lorena Bordalo, Vitor Peruzi e Leonardo Bento, que participaram da pesquisa desde o início, permanecendo como colaboradores em todos os semestres em que foi oferecida uma disciplina especial de Iniciação Científica para o desenvolvimento do mapa, com pesquisa de campo nos sites das editoras para o levantamento dos nomes dos autores brasileiros em atividade a partir do ano 2000 e confecção de fichas com dados dos autores. Outros alunos tiveram participação importante em um ou dois semestres da pesquisa. São eles: Ádila Guelli, Rafaela Miranda de Oliveira, Isabela Muniz, Felipe Félix, Thaisa Resende, Thainá Marinho, Joaquim Mamede Neto, Felipe Medeiros, Natacha Machado, Elisa Santana, Beatriz Cruz, Manuela Imamura, Luis Fellipe dos Santos, Dandara Ribeiro Pinto e Danilo Diógenes. Agradeço a todos esses alunos e a minha supervisora, Beatriz Resende.
} 
São Paulo, o Jabuti e o Brasil Telecom. Dessa maneira, pensamos ter dado conta do mapeamento o mais completo possível dos autores em atividade no período de 2000 a 2014.

O mapa resultante da pesquisa mostra os seguintes dados de cada autor: nome, editora, idade, local de nascimento e de atuação, profissão, número de livros publicados por gênero, período e regularidade da publicação, prêmios, bolsa ou incentivos de toda natureza, traduções na América Latina (destacados Argentina e México, principais países com presença de literatura brasileira nas livrarias), tradução na Europa (França e Alemanha em destaque pelo recente investimento brasileiro nesses dois países, Espanha em destaque pela língua e pelo mercado que poderia ser impulsionado pela América Latina ou vice-versa; Itália, por ser considerado um lugar de forte atuação nos estudos de pesquisadores sobre o Brasil e Inglaterra pela língua comum com os EUA) e tradução nos Estados Unidos. Para dar conta da visibilidade interna desses autores, o que talvez seja de maior interesse aqui, destacamos a participação na Flip, a presença ou citação na mídia escrita, na televisiva e na rede. Relacionando a regularidade da produção, os prêmios e a visibilidade nas três mídias procuramos detectar o grau (baixo, médio, médio-baixo, médio-alto e alto) de visibilidade no sistema literário nacional dos autores. Essa etapa foi a mais difícil e foram feitos numerosos debates para chegarmos a algum consenso nem sempre plenamente aceitável, já que há autores com visibilidade alta na rede e baixa nas outras mídias, bem como autores altamente reconhecidos no Sul ou no Nordeste e pouco conhecidos no Sudeste e vice-versa. Optamos, assim, por atribuir o grau de visibilidade com vistas à extensão da citação do autor no Google (a que chamamos visibilidade na rede) + número de resenhas em jornais de grande circulação (que aparecem na busca no Google) + prêmios + traduções + regularidade na produção.

A proposição a que se lançou a pesquisa foi justamente buscar entre os menos visíveis aqueles que têm uma produção que instigue ao estudo. Dessa maneira, pensamos construir algum outro lugar de leitura que não dependa exclusivamente da projeção do autor no mercado em termos de visibilidade. Se esse lugar de leitura terá consequência ou não em termos de novas visibilidades, nesse momento, é uma questão de pouca importância. A importância maior me parece ser justamente a construção de uma lista outra e sempre nova de leituras que não dependa da imposição das prestigiosas listas abonadas pelas instituições ou pelo mercado. 
Ao buscar dar conta da visibilidade dos autores percebemos como alguns nomes sobem e descem no gráfico anualmente e como outros se mantém constantes. Por exemplo: Ivana Arruda Leite, paulista, nascida em 1951, começou a publicar em 1997 e não parou mais até 2014, teve alguma visibilidade em 2002 com seu livro Falo de mulher e como lançou praticamente um livro a cada ano, continuou visível, embora não tenha recebido prêmios, nem tenha sido traduzida para grande número de idiomas (apenas um livro para o catalão). É um caso de carreira construída firmemente, ela está em todas as antologias e seus livros ficaram por período relativamente longo nas livrarias das principais capitais brasileiras. Isso não impediu que seu mais recente livro, Cachorros (2014), fosse publicado por uma pequena editora, sem grandes recursos para distribuição e que a autora se anuncie como uma vendedora de seus próprios livros. No Encontros de interrogação, no Itaú Cultural em outubro de 2014, ela expõe o problema de não ser um autor que desponta, uma novidade, e com isso a dificuldade de se manter no sistema literário. Em seu blog podemos ler: "Como a Demônio Negro é uma editora pequena, quase artesanal, que faz livros lindos sob os cuidados do Vanderley Mendonça, mas não tem esquema de divulgação nem de vendas, e como eu quero muito que meus livros cheguem ao maior número possível de leitores (se não, pra que escrever?), desde outubro do ano passado [2014] venho exercendo bravamente a função de escritora-mascate e vendendo meus livros de mão em mão pelas redes sociais (afinal, alguma serventia eles têm)." ${ }^{15}$ Embora seus livros sejam comentados por comentadores de renome, em jornais de grande circulação, não se pode dizer que sua visibilidade é alta e seu nome não aparece em nenhuma das listas de autores convidados a representar o Brasil nas feiras internacionais. Ou seja, não é um nome muito visível embora tenha uma sólida produção.

Por outro lado, no mesmo encontro do Itaú Cultural, um dos autores convidados, Michel Laub, iniciou sua fala justamente com a figura do cansaço. Cansaço de ser um autor sempre requisitado e que já não tem o que falar ou já não quer falar além do que já escreveu em seus livros. Sempre nas listas dos autores escolhidos para representar o Brasil, o autor da Cia das Letras, nascido em 1973 e colaborador da Folha de S. Paulo, tem visibilidade alta e está traduzido para o alemão, o espanhol, o inglês, o francês, entre outras línguas.

${ }^{15}$ LEITE, Ivana Arruda. Cachorro e contos reunidos. Doidivana, 23 fev. 2015. 
Ganhou diversos prêmios como o Jabuti (2014, segundo lugar) o Transfuge 2014, na França; a Copa de Literatura Brasileira de 2013; o Érico Veríssimo em 2001; o Bravo em 2011 e foi finalista do São Paulo de Literatura em 2012 e 2014; do Brasil Telecom em 2005, 2007 e 2012; do Wingate, 2014, na Inglaterra; do Corrente de Escrita, 2014, em Portugal e do Záfari \& Bourbon em 2005 e em 2011.

Essa condição de cansaço que a visibilidade dá faz lembrar de Léo Richter, personagem do livro Fama, de Daniel Kehlmann ${ }^{16}$, sempre à beira de um colapso toda vez que encontra seus leitores em perdidas cidades do mundo, alemães também perdidos, a trabalho em países longínquos que insistem sempre na mesma pergunta: "De onde você tira suas ideias?" a que ele sempre responde: "Na banheira". E fim de conversa.

Os encontros literários destinados por um lado a formar e a informar leitores para justificar a existência de escritores e por outro para que os escritores possam dizer que vivem de literatura (porque não vivem da venda de seus livros, claro) não estariam errando em algum lugar quando cedem à pressão de agentes e editoras expondo excessivamente alguns autores e ignorando a existência de outros? Estaria tudo resumido a uma questão de ignorância, afinal o Brasil é grande e é impossível conhecer 500 autores contemporâneos? Ou, finalmente, só aqueles que provaram serem capazes de conquistar visibilidade tem mesmo algo a nos dizer e o direito de serem lidos?

\footnotetext{
${ }^{16}$ KEHLMANN, Daniel. Fama. Um romance em nove histórias. Trad. Sonali Bertuol. São Paulo: Companhia das Letras, 2011.
} 